\title{
The evaluation of visibility of mandibular anatomic landmarks using panoramic radiography
}

\author{
Gözde Serindere ${ }^{1}\left(\mathbb{D}\right.$, Ceren Aktuna Belgin ${ }^{1}(\mathbb{C}$ \\ ${ }^{1}$ Hatay Mustafa Kemal University, Faculty of Dentistry, Department of Dentomaxillofacial Radiology, Hatay, Turkey.
}

\section{Correspondence:}

\section{Dr. Gözde SERINDERE}

Hatay Mustafa Kemal University, Faculty of Dentistry, Department of Dentomaxillofacial Radiology, Hatay, Turkey.

E-mail:gozdeserindere@mku.edu.tr

Received: 6 May 2019

Accepted: 26 July 2019

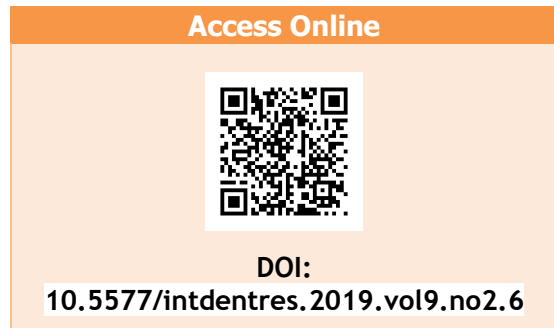

\section{Introduction}

The radiologically diagnosis of a pathology requires a certain knowledge of anatomic landmarks. This diagnosis cannot be made without knowing the variations of anatomical structures (1).

Knowledge of the morphological and anatomical variations related to anatomic landmarks of the mandible is necessary in implant surgery, especially for the inferior alveolar nerve bundlebecause it exists
Aim: The mandibular canal, mandibular foramen, mental foramen, and incisive canal are important anatomical structures for dental surgery. The aim of this study was to evaluate the visibility of these important landmarks in different age groups and to compare the visibility in the dentulous group with the edentulous group on panoramic radiographs.

Methodology: Panoramic radiographs of 500 patients ( 237 males and 263 females; mean age:39.2) were evaluated for this study; the visibility of their anatomical landmarks was analyzed, and scores were noted. The data obtained were analyzed using the SPSS 21 package program. The value of $\mathrm{p}<0.05$ was considered statistically significant.

Results: The mandibular canal, mandibular foramen, mental foramen, and incisive canal were visible in $89.8 \%, 88 \%, 80.6 \%$, and $12.8 \%$ of all radiographs, respectively.Twenty-three $(4.6 \%)$ patients had total tooth loss. The visibility of the anatomical landmarks were most clearly observed in groups below 25 years old.

Conclusions: Panoramic radiographs provide useful information on the visibility of anatomical landmarks. However, using 3D imaging methods before surgical procedures will provide more accurate results.

Keywords: Panoramic radiography, mandible, anatomical landmark

How to cite this article: Serindere G, Aktuna Belgin C. The evaluation of visibility of mandibular anatomic landmarks using panoramic radiography. Int Dent Res 2019;9(2):69-77. 
loop after traversing a short behind pathway before returning into the mandible (4). Currently, several surgeons work on the anterior region of the mandible (intermental area) involving implant placement, orthognathic surgery, and screw fixation. The intermental area is presumed to be safe for surgical operations, and theoccurrence of a mandibular incisive canal is a problem in this region. The inferior alveolar nerve may extend beyond the mental foramen as an intraosseous anterior loop. The mandibular canal includes the inferior alveolar nerve and blood vessels. It is divided into mental and incisive branches. In some cases, the radiologically visibility ofthe incisive branches may be seen (5).

Radiography is a non-invasive method for diagnosis and treatment planning before surgical operationsin the mandible. The panoramic radiography technique is a curved plane tomographic radiographic modality, in which the mandibular canal seems to be a radiolucent line limited by two outer radiopaque lines. The mandibular canal starts at the mandibular foramen and reaches the mental foramen. Panoramic radiographsare usually magnified and have anatomical structure superimposition. However, panoramic radiography has some advantages, such as being cost effective andeasily accessible and requiringa minimum amount of time to obtain a radiograph. Therefore, panoramic radiography is widely used for diagnosing, imaging, and deciding the best surgical treatment options (6).

In light of this information, the aim of this study was to evaluate the visibility of mandibular anatomic landmarks on panoramic radiographs.

\section{Materials and Methods}

After obtaining ethical approval, 500 digital panoramic radiographs of patients who were referred to the Department of Dentomaxillofacial Radiology in the Faculty of Dentistry, Hatay Mustafa Kemal University, were retrospectively evaluated. These radiographs were obtained using the Vatech panoramic imaging device (Vatech Global, Korea). All images were evaluated by two dentomaxillofacial radiologists (GS and $(A B)$ with the same Planmeca Romexis software program. The patients' gender and age were recorded.
Patientswere divided into six age groups: 14-24, 25-34, 35-44, 45-54, 55-64, and 65+ years.

Radiographs with inadequate quality, with artifacts to prevent the appearance of the mandible, and with fractures or pathologies in the mandible were excluded from the study. Anatomical structures in the mandible (mandibular canal, mandibular foramen, mental foramen, and incisive canal) were classified according to a visibility scale reported by Singh et al. (7) and Nagaraj et al. (8), which consists of four components: good visibility (above average), moderate visibility (average), poor visibility (below average), and invisibility. Data were recorded and analyzed statistically, and the interobserver agreement was calculated using the intraclass correlation coefficient (ICC).

\section{Statistical Analysis}

The data obtained in this study were analyzed using the SPSS 21 package program. Dependence between variables was analyzed by Chi-Square analysis. The significance level used was 0.05; there was a significant difference/dependency in the case of $p$ $<0.05$ and no significant difference/dependence in the case of $p>0.05$.

\section{Results}

The interobserver agreement was very high and meaningful (ICC at 0.7 and above indicates a good agreement) (Table 1). The subjects included 237 males (47.4\%) and 263 females (52.6\%). Twenty-three subjects were completely edentulous and 477 were dentate, with the age range of 14 to 81 years and the mean age of 39.2 years (Table 2 ). The mandibular canal, mandibular foramen, mental foramen and incisive canal were visible in $89.8 \%, 88 \%, 80.6 \%$, and $12.8 \%$ of the cases, respectively (Graph. 1-3, Fig. 1 , and Table 3). Anatomic landmarks were frequently visiblein the 14-24 age group and were the least visible in patients over 65 years old.

Table 1. Interobserver agreement

\begin{tabular}{l|cc}
\hline & ICC & p \\
\hline Mandibular canal & 0,927 & 0,0001 \\
\hline Mandibular foramen & 0,951 & 0,0001 \\
Mental foramen & 0,983 & 0,0001 \\
\hline Incisive canal & 0,922 & 0,0001 \\
\hline
\end{tabular}


Table 2. The patient number according to the age groups

\begin{tabular}{c|ccc|}
\hline & & $\mathbf{n}$ & $\%$ \\
\hline & $14-24$ & 133 & 26,6 \\
\hline \multirow{3}{*}{ Age } & $25-34$ & 90 & 18,0 \\
groups & $35-44$ & 82 & 16,4 \\
& $45-54$ & 90 & 18,0 \\
& $55-64$ & 54 & 10,8 \\
& $65+$ & 51 & 10,2 \\
\hline
\end{tabular}

Table 3. The visibility rates

\begin{tabular}{|c|c|c|c|}
\hline & & $\mathbf{n}$ & $\%$ \\
\hline \multirow{3}{*}{ Gender } & Male & 237 & 47,4 \\
\hline & Female & 263 & 52,6 \\
\hline & Total & 500 & 100,0 \\
\hline \multirow{5}{*}{ Mandibular canal } & Invisible & 51 & 10,2 \\
\hline & Poor visibility & 176 & 35,2 \\
\hline & Moderate visibility & 189 & 37,8 \\
\hline & Good visibility & 84 & 16,8 \\
\hline & Total & 500 & 100,0 \\
\hline \multirow{5}{*}{ Mandibular foramen } & Invisible & 60 & 12,0 \\
\hline & Poor visibility & 179 & 35,8 \\
\hline & Moderate visibility & 182 & 36,4 \\
\hline & Good visibility & 79 & 15,8 \\
\hline & Total & 500 & 100,0 \\
\hline \multirow{5}{*}{ Mental foramen } & Invisible & 97 & 19,4 \\
\hline & Poor visibility & 177 & 35,4 \\
\hline & Moderate visibility & 145 & 29,0 \\
\hline & Good visibility & 81 & 16,2 \\
\hline & Total & 500 & 100,0 \\
\hline \multirow{5}{*}{ Incisive canal } & Invisible & 436 & 87,2 \\
\hline & Poor visibility & 49 & 9,8 \\
\hline & Moderate visibility & 12 & 2,4 \\
\hline & Good visibility & 3 & ,6 \\
\hline & Total & 500 & 100,0 \\
\hline \multirow{3}{*}{ Dental status } & Edentulous & 23 & 4,6 \\
\hline & Dentulous & 477 & 95,4 \\
\hline & Total & 500 & 100,0 \\
\hline
\end{tabular}




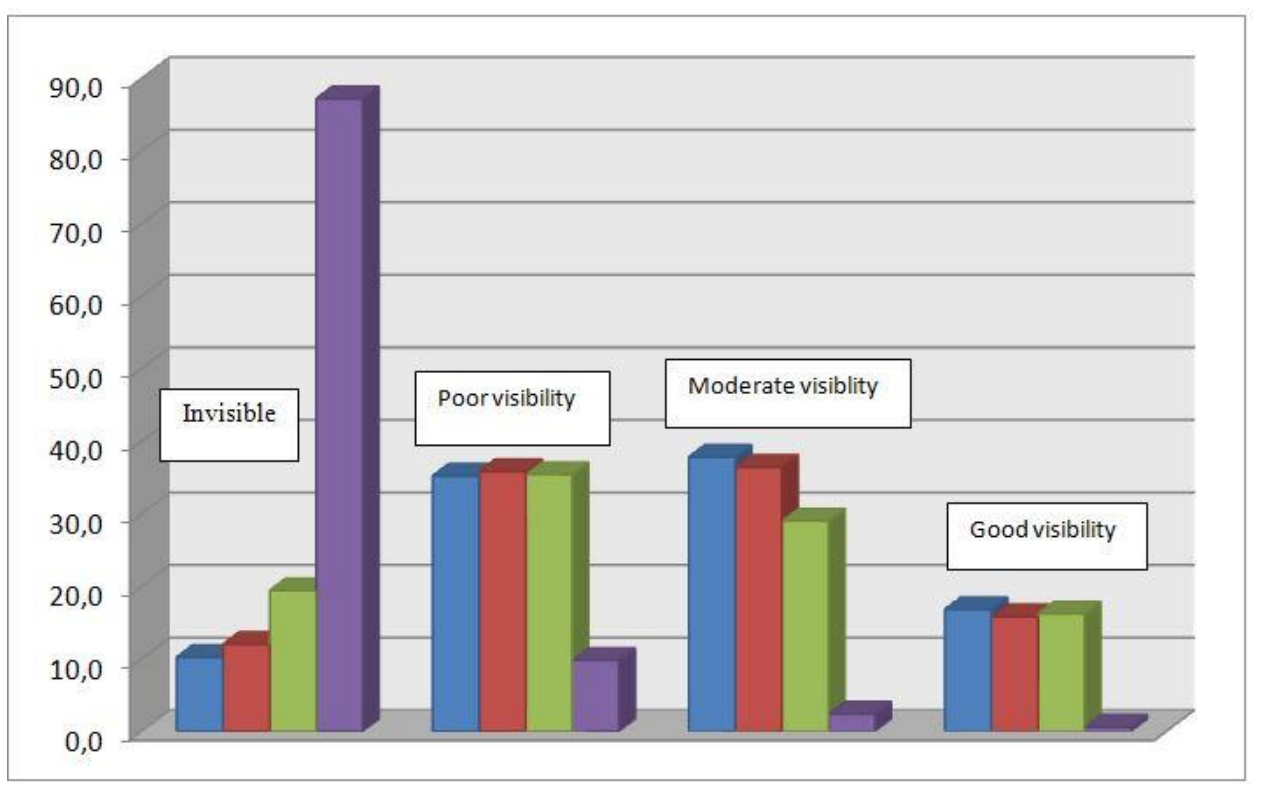

Graphic 1. Visibility rates of mandibular canal (blue), mandibular foramen (red), mental foramen (green) and incisive canal (purple)
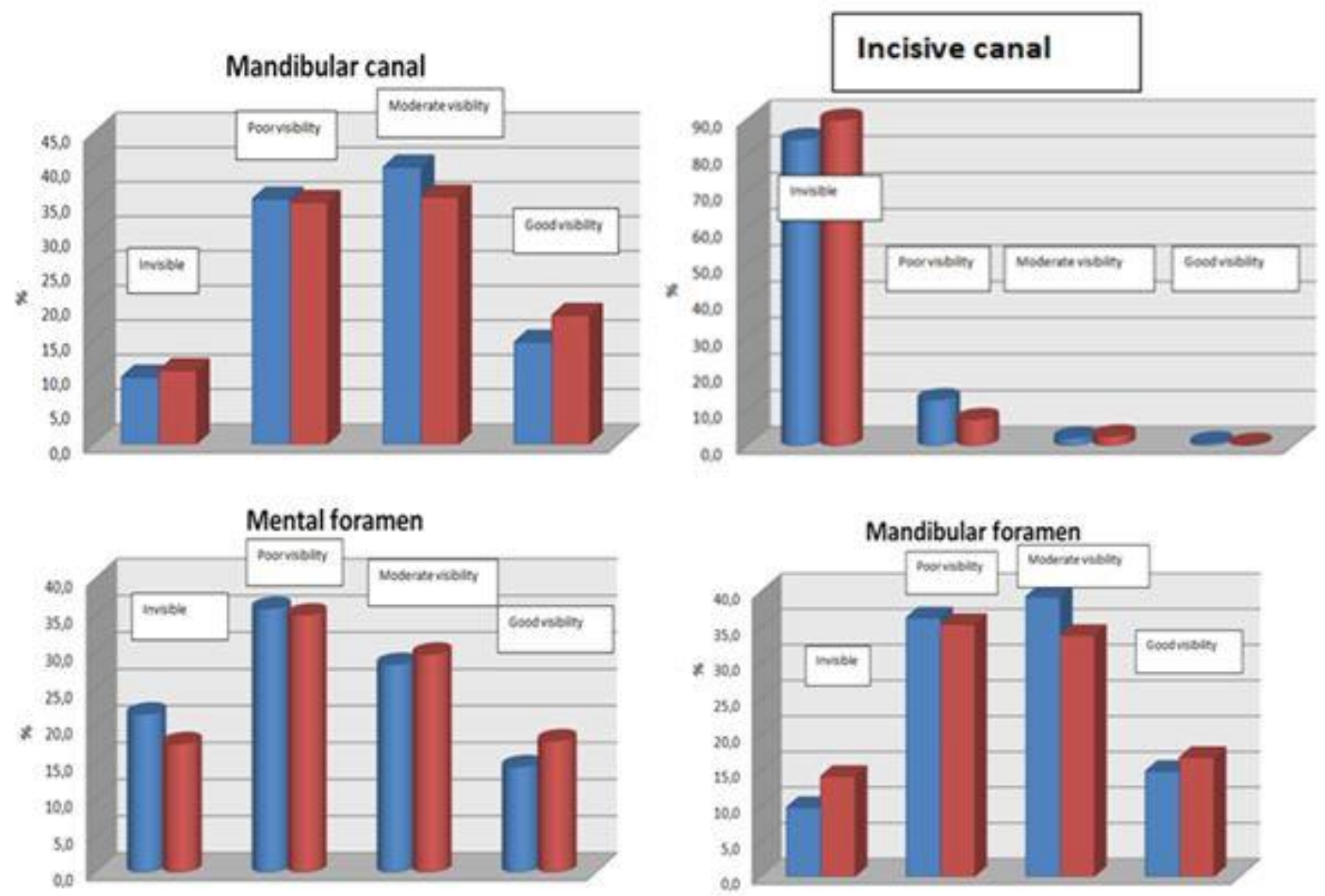

Graphic 2. Visibility rates for males (blue) and females (red) 


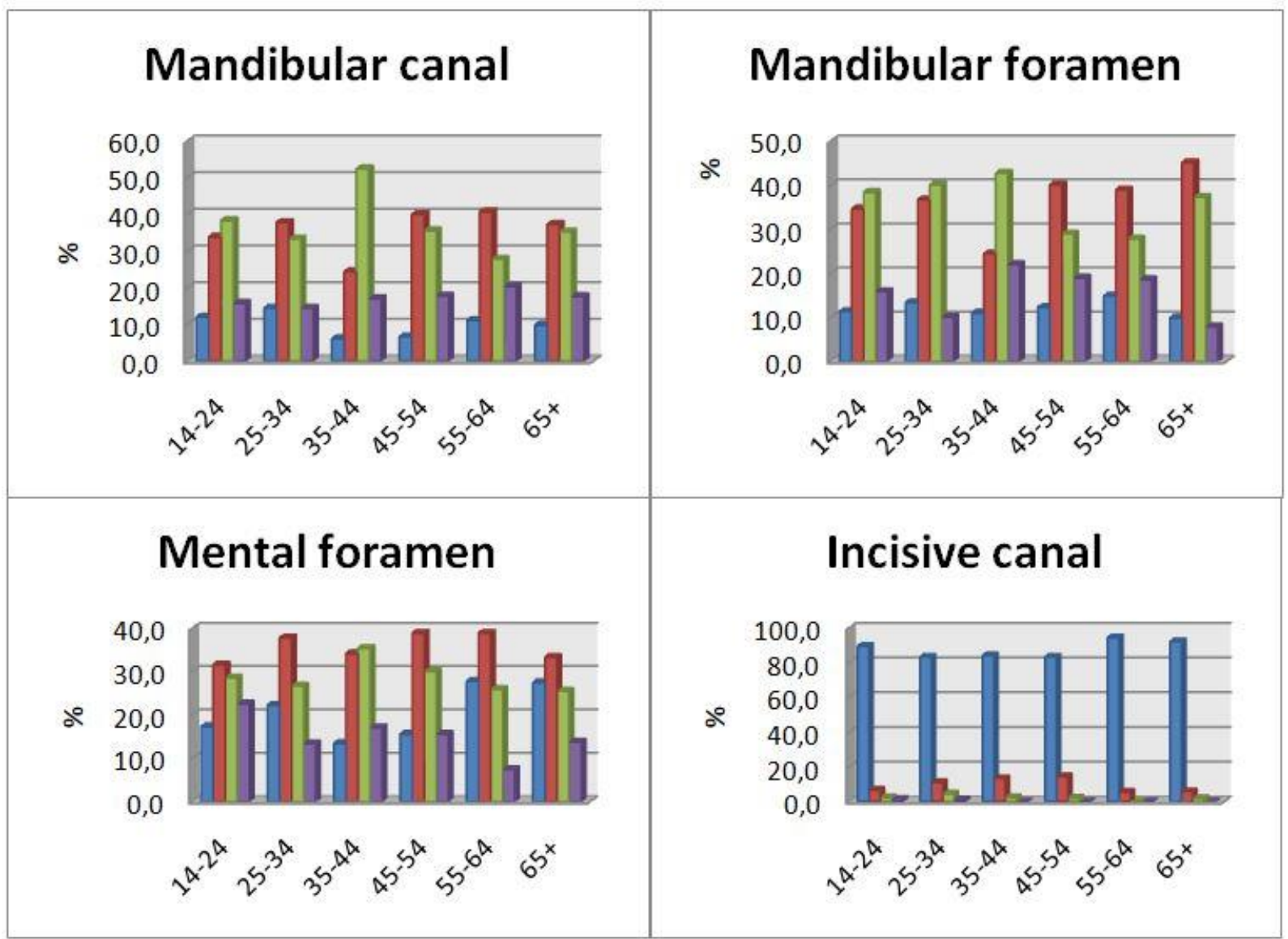

Graphic 3. Visibility rates according to the age groups (blue: invisible, red: poor visibility, green: moderate visibility, purple: good visibility)

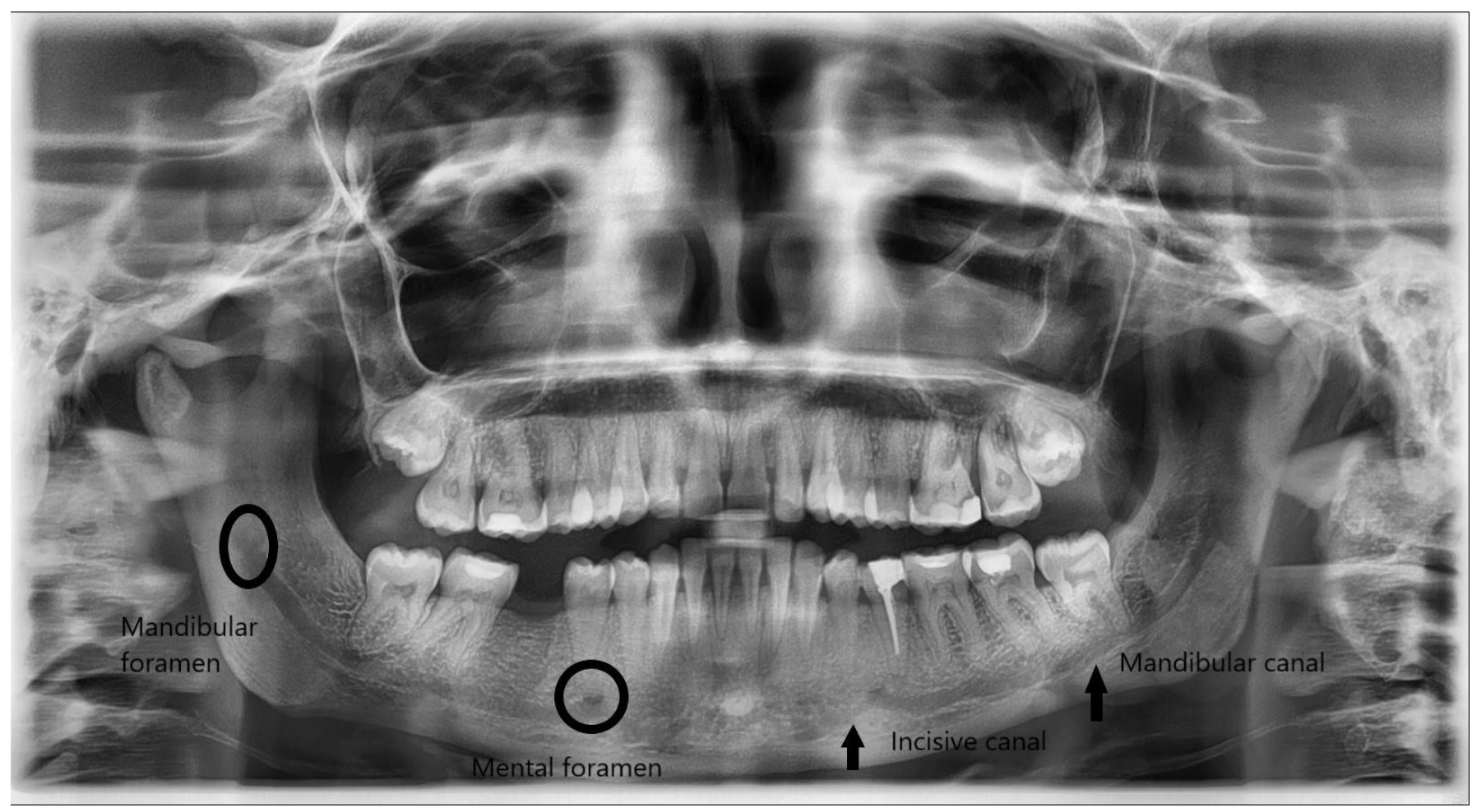

Figure 1. Assessed anatomical landmarks on panoramic radiograph 
The following statistical results were observed (Tables 4-6):

- There were no significant differences between gender and the visibility of the mandibular canal $(p>0.05)$; however, the good visibility rate was highest in females(18.6\%).

- There were no significant differences between gender and the visibility of the mandibular foramen $(p>0.05)$; however, the invisibilityrate was highest in females $(14.1 \%)$. The rate of moderate visibility in males was $39.2 \%$.

- There were no significant differences between gender and the visibility of the mental foramen ( $p>0.05)$; however, the good visibility ratewas highest in females (17.9\%).

- There were no significant differences between gender and the visibility of incisive canal $(p>0.05)$; however, the invisibility rate was highest in females $(89.7 \%)$.

- There were no significant differences between the age groups and the visibility of the mandibular canal ( $p>0.05$ ); however, the visibility rates were highest in the 35 and over age groups.

- There were no significant differences between the age groups and the visibility of the mandibular foramen cases $(p>0.05)$; however, the good visibility rate was highest in the 35-65 age group.

- There were no significant differences between the age groups and the visibility of the mental foramen
( $p>0.05)$; however, the good visibility rate was highest in the 14-24age group.

- There were no significant differences between the age groups and the visibility of the incisive canal $(p>0.05)$; however, good visibility rates were highest in the 55+ age groups.

- There were no significant differences between the edentulous group and the visibility of the mandibular canal $(p>0.05)$. Although not statistically significant, the good visibility rate in the edentulous group was higher than dentulous group.

- There were significant differences between the edentulous group and the visibility of the mandibular foramen $(p<0.05)$. The good visibility rate in the dentulous group was significantly higher than edentulous group ( $p<0.05)$.

- There were no significant differences between the edentulous group and the visibility of the mental foramen $(p>0.05)$. Although not statistically significant, the invisibility rate in the edentulous group was higher than dentulous group.

- There were no significant differences between the edentulous group and the visibility of the incisive canal $(p>0.05)$. Although not statistically significant, the invisibility rate was higher in the edentulous group.

Table 4. The visibility of anatomical landmarks according to gender

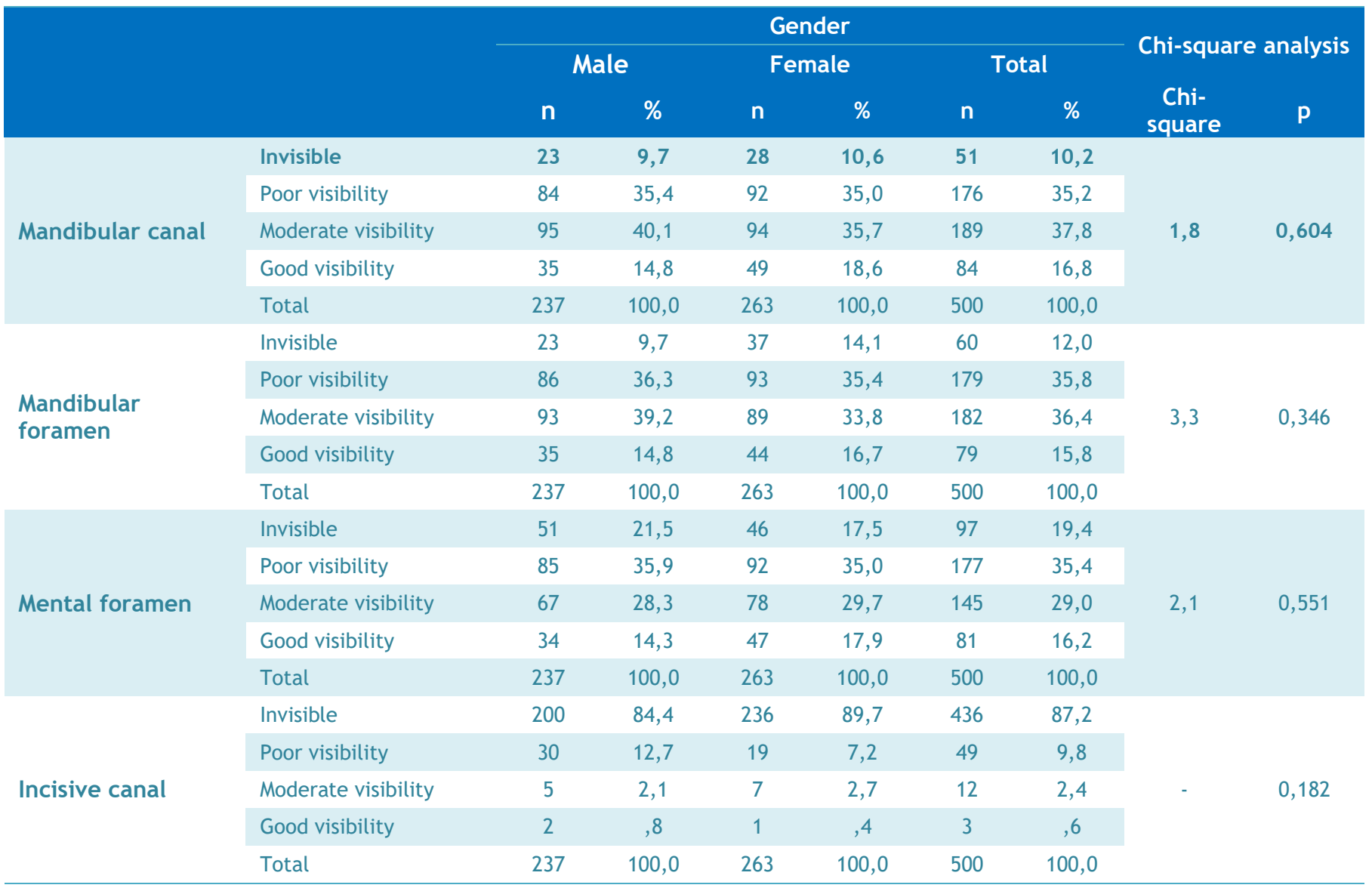


Table 5. The visibility of anatomical landmarks according to the age groups

\begin{tabular}{|c|c|c|c|c|c|c|c|c|c|c|c|c|c|c|c|c|c|}
\hline & & \multicolumn{14}{|c|}{ Age groups } & \multirow{2}{*}{\multicolumn{2}{|c|}{$\begin{array}{c}\text { Chi-square } \\
\text { analysis }\end{array}$}} \\
\hline & & \multicolumn{2}{|c|}{$14-24$} & \multicolumn{2}{|c|}{$25-34$} & \multicolumn{2}{|c|}{$35-44$} & \multicolumn{2}{|c|}{$45-54$} & \multicolumn{2}{|c|}{$55-64$} & \multicolumn{2}{|c|}{$65+$} & \multicolumn{2}{|c|}{ Total } & & \\
\hline & & $\mathbf{n}$ & $\%$ & $\mathbf{n}$ & $\%$ & $n$ & $\%$ & $\mathbf{n}$ & $\%$ & $\mathbf{n}$ & $\%$ & $\mathbf{n}$ & $\%$ & $\mathbf{n}$ & $\%$ & $\begin{array}{l}\text { Chi- } \\
\text { square }\end{array}$ & p \\
\hline \multirow{5}{*}{$\begin{array}{l}\text { Mandibular } \\
\text { canal }\end{array}$} & Invisible & 16 & 12,0 & 13 & 14,4 & 5 & 6,1 & 6 & 6,7 & 6 & 11,1 & 5 & 9,8 & 51 & 10,2 & \multirow{5}{*}{16,2} & \multirow{5}{*}{0,365} \\
\hline & $\begin{array}{l}\text { Poor } \\
\text { visibility }\end{array}$ & 45 & 33,8 & 34 & 37,8 & 20 & 24,4 & 36 & 40,0 & 22 & 40,7 & 19 & 37,3 & 176 & 35,2 & & \\
\hline & $\begin{array}{l}\text { Moderate } \\
\text { visibility }\end{array}$ & 51 & 38,3 & 30 & 33,3 & 43 & 52,4 & 32 & 35,6 & 15 & 27,8 & 18 & 35,3 & 189 & 37,8 & & \\
\hline & $\begin{array}{l}\text { Good } \\
\text { visibility }\end{array}$ & 21 & 15,8 & 13 & 14,4 & 14 & 17,1 & 16 & 17,8 & 11 & 20,4 & 9 & 17,6 & 84 & 16,8 & & \\
\hline & Total & 133 & 100,0 & 90 & 100,0 & 82 & 100,0 & 90 & 100,0 & 54 & 100,0 & 51 & 100,0 & 500 & 100,0 & & \\
\hline \multirow{5}{*}{$\begin{array}{l}\text { Mandibular } \\
\text { foramen }\end{array}$} & Invisible & 15 & 11,3 & 12 & 13,3 & 9 & 11,0 & 11 & 12,2 & 8 & 14,8 & 5 & 9,8 & 60 & 12,0 & \multirow{5}{*}{16,267} & \multirow{5}{*}{0,364} \\
\hline & $\begin{array}{l}\text { Poor } \\
\text { visibility }\end{array}$ & 46 & 34,6 & 33 & 36,7 & 20 & 24,4 & 36 & 40,0 & 21 & 38,9 & 23 & 45,1 & 179 & 35,8 & & \\
\hline & $\begin{array}{l}\text { Moderate } \\
\text { visibility }\end{array}$ & 51 & 38,3 & 36 & 40,0 & 35 & 42,7 & 26 & 28,9 & 15 & 27,8 & 19 & 37,3 & 182 & 36,4 & & \\
\hline & $\begin{array}{l}\text { Good } \\
\text { visibility }\end{array}$ & 21 & 15,8 & 9 & 10,0 & 18 & 22,0 & 17 & 18,9 & 10 & 18,5 & 4 & 7,8 & 79 & 15,8 & & \\
\hline & Total & 133 & 100,0 & 90 & 100,0 & 82 & 100,0 & 90 & 100,0 & 54 & 100,0 & 51 & 100,0 & 500 & 100,0 & & \\
\hline \multirow{5}{*}{$\begin{array}{l}\text { Mental } \\
\text { foramen }\end{array}$} & Invisible & 23 & 17,3 & 20 & 22,2 & 11 & 13,4 & 14 & 15,6 & 15 & 27,8 & 14 & 27,5 & 97 & 19,4 & \multirow{5}{*}{16,1} & \multirow{5}{*}{0,371} \\
\hline & $\begin{array}{l}\text { Poor } \\
\text { visibility }\end{array}$ & 42 & 31,6 & 34 & 37,8 & 28 & 34,1 & 35 & 38,9 & 21 & 38,9 & 17 & 33,3 & 177 & 35,4 & & \\
\hline & $\begin{array}{l}\text { Moderate } \\
\text { visibility }\end{array}$ & 38 & 28,6 & 24 & 26,7 & 29 & 35,4 & 27 & 30,0 & 14 & 25,9 & 13 & 25,5 & 145 & 29,0 & & \\
\hline & $\begin{array}{l}\text { Good } \\
\text { visibility }\end{array}$ & 30 & 22,6 & 12 & 13,3 & 14 & 17,1 & 14 & 15,6 & 4 & 7,4 & 7 & 13,7 & 81 & 16,2 & & \\
\hline & Total & 133 & 100,0 & 90 & 100,0 & 82 & 100,0 & 90 & 100,0 & 54 & 100,0 & 51 & 100,0 & 500 & 100,0 & & \\
\hline \multirow{5}{*}{$\begin{array}{l}\text { Incisive } \\
\text { canal }\end{array}$} & Invisible & 119 & 89,5 & 75 & 83,3 & 69 & 84,1 & 75 & 83,3 & 51 & 94,4 & 47 & 92,2 & 436 & 87,2 & \multirow{5}{*}{-} & \multirow{5}{*}{0,528} \\
\hline & $\begin{array}{l}\text { Poor } \\
\text { visibility }\end{array}$ & 9 & 6,8 & 10 & 11,1 & 11 & 13,4 & 13 & 14,4 & 3 & 5,6 & 3 & 5,9 & 49 & 9,8 & & \\
\hline & $\begin{array}{l}\text { Moderate } \\
\text { visibility }\end{array}$ & 3 & 2,3 & 4 & 4,4 & 2 & 2,4 & 2 & 2,2 & 0 & 0,0 & 1 & 2,0 & 12 & 2,4 & & \\
\hline & $\begin{array}{l}\text { Good } \\
\text { visibility }\end{array}$ & 2 & 1,5 & 1 & 1,1 & 0 & 0,0 & 0 & 0,0 & 0 & 0,0 & 0 & 0,0 & 3 & 6 & & \\
\hline & Total & 133 & 100,0 & 90 & 100,0 & 82 & 100,0 & 90 & 100,0 & 54 & 100,0 & 51 & 100,0 & 500 & 100,0 & & \\
\hline
\end{tabular}

Table 6 . The visibility of anatomical landmarks according to the dental status

\begin{tabular}{|c|c|c|c|c|c|c|c|c|c|}
\hline & & \multicolumn{6}{|c|}{ Dental status } & \multirow{2}{*}{\multicolumn{2}{|c|}{ Chi-square analysis }} \\
\hline & & \multicolumn{2}{|c|}{ Edentulous } & \multicolumn{2}{|c|}{ Dentulous } & \multicolumn{2}{|c|}{ Total } & & \\
\hline & & $\mathbf{n}$ & $\%$ & $\mathbf{n}$ & $\%$ & $\mathbf{n}$ & $\%$ & $\begin{array}{c}\text { Chi- } \\
\text { square }\end{array}$ & p \\
\hline \multirow{5}{*}{ Mandibular canal } & Invisible & 5 & 21,7 & 46 & 9,6 & 51 & 10,2 & \multirow{5}{*}{-} & \multirow{5}{*}{0,155} \\
\hline & Poor visibility & 8 & 34,8 & 168 & 35,2 & 176 & 35,2 & & \\
\hline & Moderate visibility & 5 & 21,7 & 184 & 38,6 & 189 & 37,8 & & \\
\hline & Good visibility & 5 & 21,7 & 79 & 16,6 & 84 & 16,8 & & \\
\hline & Total & 23 & 100,0 & 477 & 100,0 & 500 & 100,0 & & \\
\hline \multirow{5}{*}{ Mandibular foramen } & Invisible & 3 & 13,0 & 57 & 11,9 & 60 & 12,0 & \multirow{5}{*}{-} & \multirow{5}{*}{0,049} \\
\hline & Poor visibility & 14 & 60,9 & 165 & 34,6 & 179 & 35,8 & & \\
\hline & Moderate visibility & 5 & 21,7 & 177 & 37,1 & 182 & 36,4 & & \\
\hline & Good visibility & 1 & 4,3 & 78 & 16,4 & 79 & 15,8 & & \\
\hline & Total & 23 & 100,0 & 477 & 100,0 & 500 & 100,0 & & \\
\hline \multirow{3}{*}{ Mental foramen } & Invisible & 6 & 26,1 & 91 & 19,1 & 97 & 19,4 & \multirow{3}{*}{ - } & \multirow{3}{*}{0,549} \\
\hline & Poor visibility & 8 & 34,8 & 169 & 35,4 & 177 & 35,4 & & \\
\hline & Moderate visibility & 4 & 17,4 & 141 & 29,6 & 145 & 29,0 & & \\
\hline
\end{tabular}




\begin{tabular}{|c|c|c|c|c|c|c|c|c|c|}
\hline & Good visibility & 5 & 21,7 & 76 & 15,9 & 81 & 16,2 & & \\
\hline & Total & 23 & 100,0 & 477 & 100,0 & 500 & 100,0 & & \\
\hline \multirow{5}{*}{ Incisive canal } & Invisible & 22 & 95,7 & 414 & 86,8 & 436 & 87,2 & \multirow{5}{*}{-} & \multirow{5}{*}{0,537} \\
\hline & Poor visibility & 1 & 4,3 & 48 & 10,1 & 49 & 9,8 & & \\
\hline & Moderate visibility & 0 & 0,0 & 12 & 2,5 & 12 & 2,4 & & \\
\hline & Good visibility & 0 & 0,0 & 3 & ,6 & 3 & ,6 & & \\
\hline & Total & 23 & 100,0 & 477 & 100,0 & 500 & 100,0 & & \\
\hline
\end{tabular}

\section{Discussion}

In this study, the visibility of important anatomical landmarks in the mandible (mandibular canal, mandibular foramen, mental foramen, and incisive canal) was evaluated on panoramic radiographs. Knowing the localizations of these important structures and obtaining sufficient visibility are important for the surgical approach so that unwanted complications and legal processes may be prevented.

Panoramic radiography is a modality used for obtaining a single tomographic image of the maxillary and mandibular arches and their supporting structures (9); it is one of the most important parts of routine dental examinations. The ease of obtaining the panoramic radiographs, the presence in almost every patient's archive, and the observability of the anatomical structures of the lower jaw were one someof the reasons that we preferred for this study.

In Nagaraj et al.'s study (8), the visibility of the mandibular canal, mental foramen, and incisive canal was present in $98 \%, 99 \%$, and $23 \%$, respectively. These results were higher than our results; the reason for this may be that our sample size was higher. Basappa et al. (10) reported that the mental foramen showed good visibility in $77 \%$, and the mandibular canal was visible in $74 \%$. The present study found higher results, likely because Basappa et al. had a smaller sample size than we did.

Jacobs et al. (11) reported the visibility of the mandibular canal as $99 \%$, with good visibility in $49 \%$ of the cases. The mental foramen could be observed in $94 \%$ of the cases, while good visibility was achieved in only $49 \%$ of the cases. The incisive canal was identified in $15 \%$ of the images, with good visibility in only $1.3 \%$; these results were lower in the present study. Jacobs et al. (11) also reported that the subjects'dental status had no effect on the visibility of anatomical structures in the interforaminal region. Similarly, in our study, there were no significant relationships between dental status and the visibility of mandibular landmarks except for the visibility of the mandibular foramen. Jalili et al. (12) reported that the mental foramen and incisive canal wereseen in $84.2 \%$ and $51.7 \%$ of the cases, respectively. The visibility of these structures was not affected by gender, but a relationship between the mandibular foramen and mandibular canal with age was found. Abesi et al. (13) and Shahidi et al. (14) reported that incisive canals were visible in $32.1 \%$ and $38 \%$ of their cases, respectively. Sakhdari et al. (15) and
Jacobs et al.'s studies (16) noted higher incisive canalvisibility results $(87.5 \%$ and $93 \%$, respectively) than our study did.We believe that this was because they used computed tomography and cone beam computed tomographyas their imaging method. However, Mardinger et al. (17) and Mwaiva et al. (18) reported an incisive canal in $80 \%$ and $96 \%$ of mandibles, respectively, which is also higher than our results. This may be a result of human cadavers being used in these studies. We think that direct observation on the cadaver can give clearer results compared to the radiographs.

In this study, anatomic landmarks were frequently visible in the 14-24 age group andthe least visible in patients over 65 years old. This may be due tobone density changes: the cortical bone becomes thicker and sclerotic with age, but the bone's collagen will decrease (19-21). Therefore, radiation absorption and transmission varies with age, causing differences in the appearance of anatomical structures (12).

\section{Conclusions}

The visibility of the mandibular canal, mandibular foramen, and mental foramen can be observed using panoramic radiography. However, it is recommended that the 3D imaging method be used as cone beam computed tomography for incisive canal imaging. The sufficient imaging of anatomical landmarks should be considered before surgical procedures in the maxillofacial region. Clinicians should carefully evaluate panoramic radiographs so that complications can be avoided and patient health and satisfaction can be guaranteed.

Ethical Approval: Ethics committee approval was received for this study from Hatay Mustafa Kemal University.

Peer-review: Externally peer-reviewed.

Author Contributions: Conception G.S., C.A.B.; Design - G.S., C.A.B.; Supervision-G.S., C.A.B.; Materials-G.S., C.A.B.; Data Collection and/or Processing-G.S.; Analysis and/or Interpretation - G.S., C.A.B.; Literature Review-G.S., Writer-G.S.; Critical Review-C.A.B.

Conflict of Interest: Noconflict of interest was declared by the authors.

Financial Disclosure: The authors declared that this study has received no financial support. 


\section{References}

1. Bhaskar SN. Radiographic interpretation for the Density. 2nd ed. St Louis: The CV. Mosby Co.; 1975. p.78-83.

2. Juodzbalys $\mathrm{G}$, Wang $\mathrm{H}$, Sabalys $\mathrm{G}$. Anatomy of mandibular vital structures. Mandibular canal and inferior alveolar neurovascular bundle in relation with dental implantology. J Oral Maxillofac Res 2010;1:1-8. (Crossref)

3. Vazquez L, Saulacic N, Belser U, Bernard JP. Efficacy of panoramic radiographs in the preoperative planning of posterior mandibular implants: a prospective clinical study of 1527 consecutively treated patients. Clin Oral Implants Res 2008;19(1):81-5. (Crossref)

4. Gerlach NL, Meijer GJ, Maal TJ, Mulder J, Rangel FA, Borstlap WA, et al. Reproducibility of 3 different tracing methods based on cone beam computed tomography in determining the anatomical position of the mandibular canal. J Oral and Maxillofac Surg 2010;68(4):811-7. (Crossref)

5. Greenstein G, Tarnow D. The mental foramen and nerve: clinical and anatomical factors related to dental implant placement: a literature review. J Periodontol 2006;77(12):1933-43. (Crossref)

6. Kapoor S, Sandhu A, Singla A, Sandhu S. Topographic anatomy of mandibular foramen in different age groups using panoramic radiographs. Eur J. Anat 2018; 22 (1): 27-35.

7. Singh N, Jaju P, Jaju S, Agarwal R. Detection of anatomical variations in mandible by panoramic radiography. J CranioMaxillary Dis 2014;3:95-100. (Crossref)

8. Nagaraj T, Keerthi I, James L, Shruthi R, Balraj L, Bhavana TV. Visibility of mandibular anatomical landmarks in panoramic radiography: A retrospective study. Journal of Medicine, Radiology, Pathology \& Surgery 2016; 2: 14-17. (Crossref)

9. White SC, Pharaoh MJ. Oral Radiology Principles and Interpretation. 5th ed. Netherlands: Elsevier Publication; 2004.

10. Srisha Basappa, Smitha JD, Nishath Khanum*, Santosh Kanwar, Mahesh MS and Archana Patil. Visibility of Maxillary and Mandibular Anatomical Landmarks in Digital Panoramic Radiographs: A Retrospective Study. Research \& Reviews: Journal of Dental Sciences 2017;5(3):36-41.
11. Jacobs R, Mraiwa N, Van Steenberghe D, Sanderink G, Quirynen $M$. Appearance of the mandibular incisive canal on panoramic radiographs. Surg Radiol Anat 2004;26:329-33. (Crossref)

12. Jalili MR, Emaeelinejad M, Bayat M, Aghdasi MM. Appearance of anatomical structures of mandible on panoramic radiographs in Iranian population. Acta Odontol Scand 2012;70:384-9. (Crossref)

13. Farida Abesi, Nima Nikafshar, Sina Haghanifar, Soraya Khafri,Mahtab Hamzeh. Can the Inversion Filter Improve the Visibility of the Mandibular Incisive Canal? Iran J Radiol 2016 January; 13(1): e22698. (Crossref)

14. Shahidi S, Zamiri B, Roosta S, Haghnegahdar A. Mandibular incisive canal on panoramic view. Dent J Shiraz Med Uni 2008;8:66-75.

15. Sakhdari S, Hafezi L, Esmaili M. Prevalence of the Inferior Alveolar Nerve's Anterior Loop and Mandibular Incisive Canal by Use of Cone Beam Computed Tomography (CBCT) in an Iranian population. J Res Dentomaxillofac Sci 2016;1(3):14-21. (Crossref)

16. Jacobs R, Mraiwa N, vanSteenberghe D, Gijbels F, Quirynen M. Appearance, location, course, and morphology of the mandibular incisive canal: an assessment on spiral CT scan. Dentomaxillofac Radiol 2002;31(2):322-7. (Crossref)

17. Mardinger O, Chaushu G, Arensburg B, Taicher S, Kaffe I. Anatomic and radiologic course of the mandibular incisive canal. Surg Radiol Anat 2000;22:157-61. (Crossref)

18. Mraiwa N, Jacobs R, Moerman P, Lambrichts I, van Steenberghe $D$, Quirynen M. Presence and course of the incisive canal in the human mandibular interforaminal region: two-dimensional imaging versus anatomical observations. Surg Radiol Anat 2003;25:416-23. (Crossref)

19. Bilezikian J, Raisz L, Rodan G. Principles of bone biology. Volume one 2nd ed. London: Academic Press; 2002. p 24-8.

20. Dechow PC, Wang Q, Peterson J. Edentulation alters material properties of cortical bone in the human craniofacial skeleton: functional implications for craniofacial structure in primate evolution. Anat Rec (Hoboken) 2010;293:618-29. (Crossref)

21. Berger C, Langsetmo L, Joseph L. Change in bone mineral density as a function of age in women and men and association with the use of antiresorptive agents. CMAJ 2008;178:1660-8. (Crossref) 